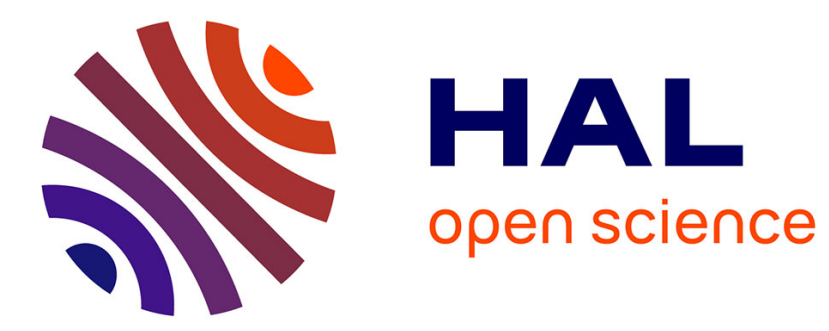

\title{
Effect of crystallization on barrier properties of formulated polylactide
}

Cécile Courgneau, S Domenek, A Guinault, Luc Avérous, Violette Ducruet

\section{To cite this version:}

Cécile Courgneau, S Domenek, A Guinault, Luc Avérous, Violette Ducruet. Effect of crystallization on barrier properties of formulated polylactide. Polymer international, 2012, 61 (2), pp.180-189. 10.1002/pi.3167 . hal-01200977

\section{HAL Id: hal-01200977 https://hal.science/hal-01200977}

Submitted on 17 Sep 2015

HAL is a multi-disciplinary open access archive for the deposit and dissemination of scientific research documents, whether they are published or not. The documents may come from teaching and research institutions in France or abroad, or from public or private research centers.
L'archive ouverte pluridisciplinaire HAL, est destinée au dépôt et à la diffusion de documents scientifiques de niveau recherche, publiés ou non, émanant des établissements d'enseignement et de recherche français ou étrangers, des laboratoires publics ou privés. 


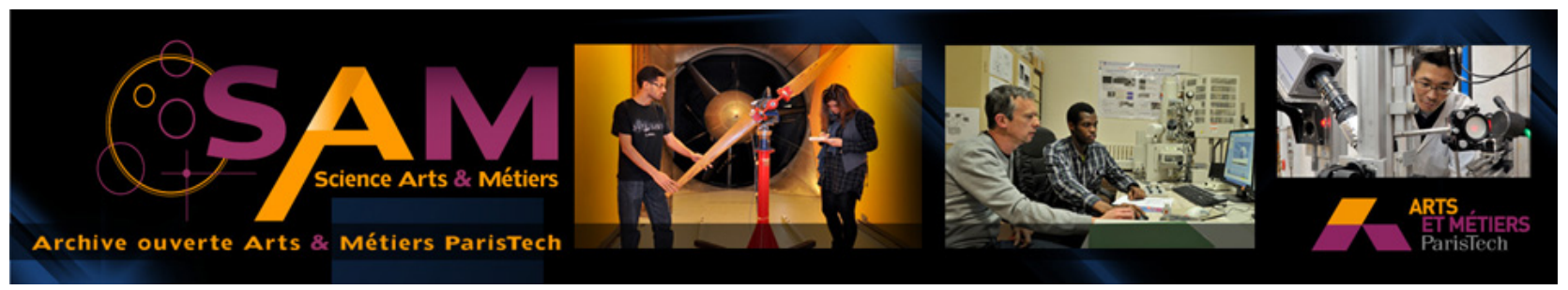

\section{Science Arts \& Métiers (SAM)}

is an open access repository that collects the work of Arts et Métiers ParisTech researchers and makes it freely available over the web where possible.

This is an author-deposited version published in: http://sam.ensam.eu

Handle ID: .http://hdl.handle.net/10985/10042

\section{To cite this version :}

Cécile COURGNEAU, S DOMENEK, Régis LEBOSSÉ, A GUINAULT, Luc AVÉROUS, Violette DUCRUET - Effect of crystallization on barrier properties of formulated polylactide - Polymer International - Vol. 61, p.180-189- 2012 


\title{
Effect of crystallization on barrier properties of formulated polylactide
}

\author{
Cécile Courgneau, ${ }^{\mathrm{a}, \mathrm{b}}$ Sandra Domenek, ${ }^{\mathrm{b}}$ Régis Lebossé, ${ }^{\mathrm{c}}$ Alain Guinault, ${ }^{\mathrm{d}}$ \\ Luc Avérous ${ }^{\mathrm{e}}$ and Violette Ducruet ${ }^{\mathrm{a} *}$
}

\begin{abstract}
Polylactide (PLA), a biodegradable polymer obtained from biomass, was formulated with a nucleating agent, talc, and a plasticizer, acetyl tributyl citrate, and cold crystallized in $\alpha$ and $\alpha^{\prime}$ form. The barrier properties of crystallized PLA were investigated as a function of the formulation and the crystalline form, thanks to three molecules with increasing polymer interactions, i.e. helium, oxygen and ethyl acetate (EA). Contrary to expectation, the oxygen diffusion coefficient in neat and formulated PLA did not decrease with crystallization. Even an increase of the diffusion coefficient was noticed for the most interacting probe, EA, in formulated PLA. Conditioning of neat and formulated PLA in an atmosphere containing EA vapour caused a modification of the material structure by plasticization and induced crystallization even at small EA activities. The plasticizing effect caused the glass transition temperature $T_{\mathrm{g}}$ to shift to below ambient temperature. In the case of neat PLA induced crystallization in solely the $\alpha$ form was obtained, and in the case of formulated PLA a blend of $\alpha$ and $\alpha^{\prime}$ forms was observed.
\end{abstract}

Keywords: polylactide; poly(lactic acid); crystallization; formulation; permeability; solvent-induced crystallization (SINC)

\section{INTRODUCTION}

Due to their environmental merits, biomass-based polymers have been widely studied, particularly polylactide (PLA). The subject of an increasing number of publications, PLA presents great interest for industrial and commodity application. ${ }^{1-3}$ Worldwide production capacity is dramatically increasing from $74 \mathrm{kt} \mathrm{p.a.} \mathrm{in}$ 2003 to 229 kt p.a. in 2009 and should amount to 833 kt p.a. in 2020. 4

Ease of processing, good mechanical properties, high glass transition temperature and high transparency make PLA a promising material for packaging or containers. However, its high brittleness and poor barrier properties restrict its application domain. The last-mentioned properties are required, for example, for packaging to preserve organoleptic food quality during shelf life by preventing alteration of food due to excessive oxygen or water vapour transfers or loss of aromatic compounds., ${ }^{5,6}$

The gas barrier properties of neat PLA have already been studied, but mainly for amorphous films. ${ }^{7-9}$ The oxygen barrier properties of amorphous PLA are similar to those of high density poly(ethylene) (HDPE) and intermediate between poly(ethylene terephthalate) (PET) and polystyrene (PS). ${ }^{10-13}$ Unlike gases, the organic molecule barrier properties of PLA have been less extensively studied. ${ }^{11,14-16}$ Auras et al. ${ }^{14}$ showed that the solubility coefficient of limonene in PLA is lower than that in PET, PS, polypropylene (PP), HDPE and low density poly(ethylene) (LDPE). ${ }^{16}$ Ethyl acetate (EA), a solvent largely used in inks and adhesives, showed in contrast a comparatively higher solubility coefficient in PLA. To give an example, the solubility coefficient of EA can be twofold higher in PLA than in PET, PP and LDPE.

One way to improve the barrier properties of semicrystalline polymers is to increase their crystallinity. Crystalline zones are presumed to be excluded volumes through which molecules cannot diffuse and in which they cannot sorb, ${ }^{17}$ in contrast to amorphous zones where diffusion is possible. However, according to the study of Kanehashi et al. ${ }^{18}$ on 300 crystalline or liquid crystalline polymers, the permeability and diffusion coefficients of gas are not significantly affected by crystallinity at low crystallinity degree. The influence of crystallinity on the barrier properties has been rarely studied for PLA and has led to contradictory results due to the lack of knowledge about the crystalline structure of the materials studied, in particular in the case of $P(D, L) L A$.

The crystalline morphology of PLA depends on its stereochemistry, ${ }^{19}$ crystallization kinetics ${ }^{20,21}$ and temperature $\left(T_{\mathrm{c}}\right)$, and its thermal history (cold or melt crystallization). ${ }^{22-24}$

Furthermore, PLA is known for its low crystallization rate. ${ }^{28,31}$ Nevertheless, similarly to other semicrystalline polymers, decreas-

\footnotetext{
* Correspondence to: Violette Ducruet, INRA UMR 1145 Ingénierie Procédés Aliments, 1 avenue des Olympiades, F 91300 Massy, France.

E-mail:violette.ducruet@agroparistech.fr

a INRA UMR 1145 Ingénierie Procédés Aliments, 1 avenue des Olympiades, F 91300 Massy, France

b AgroParisTech UMR 1145 Ingénierie Procédés Aliments, 1 avenue des Olympiades, F 91300 Massy, France

c LNE, Laboratoirenationaldemétrologieet d'Essais, 29avenueRogerHennequin, 78197 Trappes CEDEX, France

d CNAM, Laboratoire P2AM, 292 rue Saint-Martin, case courrier 322, 75141 Paris CEDEX 03, France

e ECPM-LIPHT, EAC (CNRS) 4379, Université de Strasbourg, 25 rue Becquerel, 67087 Strasbourg CEDEX 2, France
} 
ing the nucleation activation energy and increasing the mobility of the chain segments are key elements to increasing the PLA crystallization rate. ${ }^{25-27}$ An efficient way to decrease the nucleation activation is to add a nucleating agent whereas the mobility of the chain segment can rise due to the addition of plasticizer.

Several nucleating agents have been tested on PLA. An example is the stereocomplex of $P(L) L A$ and $P(D) L A,{ }^{28,29}$ which induces a decrease of the crystallization half-time of $P(L) L A$ at an incorporation content less than $10 \mathrm{wt} \%$. Some research has shown that organic compounds can be successful in playing the role of a nucleating agent. $\mathrm{N}, \mathrm{N}$-ethylene-bis-12-hydroxystereamide leads to an increase of the nucleation density (multiplied by 10) and crystallization rate (from 5 to 20 times). ${ }^{30,31}$ Kawamoto et al. have shown that other organic compounds based on hydrazide groups can increase the crystallization temperature upon cooling. ${ }^{32}$ Other nucleating agents, such as sodium salts, calcium lactate, $\mathrm{CaCO}_{3}$, $\mathrm{TiO}_{2}$ and $\mathrm{BaSO}_{4}$, have demonstrated a lower efficiency. ${ }^{33,34}$ Data show that these substances are less efficient than talc, which is widely used as a nucleating agent since the crystallization rate is 65-fold higher than that of PLA alone. ${ }^{31,34,35}$

Various types of plasticizers have been used to modify the PLA properties, such as oligomeric lactic acid, ${ }^{36}$ triacetine, $^{37} \mathrm{di}-$ ethyl bishydroxymethyl malonate, ${ }^{38}$ poly(1,2-butanediol), dibutyl sebacate acetyl glycerol monolaurate, ${ }^{39}$ triphenyl phosphate, ${ }^{25}$ polyadipates, ${ }^{40,41}$ poly(propylene glycol), ${ }^{42,43}$ poly(ethylene glycol) $^{36,43-46}$ and acetyl tributyl citrate. ${ }^{37,44,47,48}$ The majority of these plasticizers are approved for food contact. ${ }^{49,50}$ According to the literature, acetyl tributyl citrate (ATBC) seems to be the most efficient plasticizer because, in addition to being approved by the US Food and Drug Administration, it efficiently decreases the glass transition temperature and improves significantly the mechanical properties of PLA. $44,47,48,51$

Consequently, the formulation of PLA with both talc and ATBC appears as a good way to increase the crystallization rate of PLA and should induce an improvement of the barrier properties. The purpose of this paper is to assess the relationships between the crystallization and the gas (helium and oxygen) and EA barrier properties of neat and formulated $P(D, L) L A$. The mechanical properties were also tested on neat and formulated PLA, before and after annealing. The crystalline structure of the neat and formulated recrystallized PLA was determined by DSC and with wide angle $\mathrm{X}$-ray diffraction (WAXD).

\section{EXPERIMENTAL}

\section{Materials}

The PLA pellets were provided by NatureWorks (Minnetonka, USA). The content of L-lactide was about $92 \mathrm{wt} \%$. The weight average molecular weight was $9.0 \times 10^{4} \mathrm{~g} \mathrm{~mol}^{-1}$ with a dispersity (D) of 2.75 .

ATBC, used as a plasticizer, was purchased from Sigma Aldrich (Saint Quentin Fallavier, France). Talc, used as a nucleating agent, was provided by RioTinto (Luzenac, France). EA and hexadecane were supplied by Sigma Aldrich (Saint Quentin Fallavier, France).

\section{Sample preparation}

PLA pellets, plasticizer and nucleating agent were dried at $80^{\circ} \mathrm{C}$ overnight in a vacuum oven. After that, the formulated PLA samples were prepared by direct melt mixing of the additives with PLA in an internal mixer (Haake Rheocord 9000 ) at $160^{\circ} \mathrm{C}$ and $60 \mathrm{rpm}$ for $15 \mathrm{~min}$. Concentrations of ATBC and talc were $17 \mathrm{wt} \%$ and $1 \mathrm{wt} \%$ in the blend, respectively.
To decrease the water content, the materials were dried for $4 \mathrm{~h}$ minimum at $80^{\circ} \mathrm{C}$ before processing. PLA samples were transformed by thermo-compression (Telemecanique, $15 \mathrm{t}$ ) at $185^{\circ} \mathrm{C}$ and 150 bars (15 GPa) to obtain a film of approximately $300 \mu \mathrm{m}$ thickness. After compression, the films were quenched to ambient temperature. Non-annealed films were stored at ambient temperature in a desiccator with $\mathrm{P}_{2} \mathrm{O}_{5}$.

The films were annealed in an air-circulating oven (Angeltoni Climatic System Massa Martana Type TY80) at the recrystallization temperature $\left(90\right.$ or $120^{\circ} \mathrm{C}$ for neat PLA and 85 or $100{ }^{\circ} \mathrm{C}$ for the formulated one) for different durations ( $90 \mathrm{~min}$ for neat PLA and 10,30 or $60 \mathrm{~min}$ for the formulated one).

\section{Conditioning of PLA film in EA atmosphere}

The annealed PLA film samples were equilibrated in an EA atmosphere at 0.2 and 0.5 activity for 2 weeks in a hermetic vessel at $25^{\circ} \mathrm{C}$ using the method published by Colomines et al. ${ }^{11}$ The 0.2 and 0.5 activities were generated by 0.8 and $2.2 \mathrm{~mol} \mathrm{~L}^{-1}$ EA solutions in hexadecane, respectively, and controlled by gas chromatography. The activity is the ratio $p / p_{0}$ with $p$ the partial pressure and $p_{0}$ the vapour pressure of EA at saturation.

\section{Analysis methods}

DSC

The thermal analyses were performed with an MDSC Q100 (TA Instruments) under a nitrogen atmosphere. The samples (about $10 \mathrm{mg}$ ) were put into hermetic aluminium pans (TZero, TA Instruments). The standard mode was used to measure isotherms from the cold state and to study the crystallization.

To investigate the kinetics of isothermal crystallization, neat and formulated PLA were heated at $190^{\circ} \mathrm{C}$ for $10 \mathrm{~min}$ to erase the thermal history of the sample and then cooled to $20^{\circ} \mathrm{C}$ and reheated to the crystallization temperature at $50^{\circ} \mathrm{C} \mathrm{min}^{-1}$. Hence the isothermal crystallization begins from $15 \mathrm{~min}$.

The half-time of crystallization, $t_{1 / 2}$, is defined as the time at which half of the final crystallinity is developed. After $3 \mathrm{~h}$ of crystallization, the sample is cooled to room temperature. Finally the sample is heated at $10^{\circ} \mathrm{C} \mathrm{min}^{-1}$ to $190^{\circ} \mathrm{C}$ to determine the melt temperature. The equilibrium melting temperatures of neat and formulated PLA are the intersection of the straight line $T_{\mathrm{m}}=f\left(T_{\mathrm{cc}}\right)$ with the line $T_{\mathrm{m}}=T_{\mathrm{cc}}$. A baseline was carried out with a sapphire at each temperature with the same thermal programme as for the PLA samples.

For analysing the degree of crystallinity of the samples $\left(\chi_{c}\right)$, heating scans were performed at a heating rate of $10^{\circ} \mathrm{C} \mathrm{min}-1$ from -30 to $190^{\circ} \mathrm{C}$. The $\chi_{c}$ of neat PLA was calculated from Eqn (1), where $\Delta H_{\mathrm{m}}$ is the enthalpy of melting, $\Delta H_{\mathrm{cc}}$ is the enthalpy of cold crystallization and $\Delta H_{\mathrm{m}}{ }^{0}$ is the enthalpy of fusion per gram of a perfect crystal of infinite size, i.e. $93 \mathrm{~J} \mathrm{~g}^{-1}:^{52}$

$$
\chi_{\mathrm{c}}=\frac{\Delta H_{\mathrm{m}}-\Delta H_{\mathrm{cc}}}{\Delta H_{\mathrm{m}}^{0}}
$$

The equivalent degree of crystallinity $\left(\chi_{\text {ce }}\right)$ of formulated PLA was calculated using Eqn (2) where $X_{P L A}$ is the weight fraction of PLA in the formulated PLA:

$$
\chi_{\mathrm{ce}}=\chi_{\mathrm{PLA}} \times \frac{\Delta H_{\mathrm{m}}-\Delta H_{\mathrm{cc}}}{\Delta H_{\mathrm{m}}^{0}}
$$

All experiments were carried out in triplicate. 
SEC

The average molecular weights were measured by SEC using a Shimadzu apparatus equipped with an RID-10A refractive index detector and an SPD-M10A UV detector. The analyses were carried out at $30^{\circ} \mathrm{C}$ and $0.8 \mathrm{~mL} \mathrm{~min}^{-1}$ in chloroform on a PL Gel $5 \mu \mathrm{m}$ Guard column and two PL Gel $5 \mu \mathrm{m}$ Mixed-C columns. The calibration was performed with PS standards from 580 to $1650000 \mathrm{~g} \mathrm{~mol}^{-1}$.

\section{WAXD}

The WAXD experiments were conducted at $50 \mathrm{kV}, 35 \mathrm{~mA}$, using $\mathrm{Cu}$ $\mathrm{K} \alpha$ radiation monochromatized with a graphite monochromator (Panalytical, X'Pert Pro MPD). The diffractograms were recorded for $2 \theta$ angles between $5^{\circ}$ and $35^{\circ}$ with a step size and time of $0.007^{\circ}$ and $368.8 \mathrm{~s}$, respectively.

The degree of crystallinity of the samples was calculated by the surface method. The ratio of the amorphous halo and the total surface of the spectrum was carried out to retrieve the amorphous phase fraction and then to find the crystallinity degree.

\section{Tensile test}

Uniaxial tensile testing was carried out at room temperature and at $5 \mathrm{~mm} \mathrm{~min}{ }^{-1}$ with an Instron tensile testing machine (Instron Model 4507) equipped with pneumatic jaws on type I BA dumbbellshaped samples. The thickness of the samples varied from 200 to $300 \mu \mathrm{m}$. Each value is an average of five measurements.

\section{Oxygen, helium and water vapour permeability}

The direct measurement of the oxygen transmission rate was monitored at $23{ }^{\circ} \mathrm{C}$ and $0 \%$ relative humidity $(\mathrm{RH})$ with a Systech 8001 apparatus. The helium transmission rate was measured at room temperature and at a relative humidity varying between $40 \%$ and $60 \% \mathrm{RH}$, by a specific analyser developed by CNAM (Paris, France), based on the ISO norm 15105-2: 2003. Oxygen and helium permeabilities were then obtained by dividing the oxygen transmission rate and helium transmission rate respectively by the film thickness. Experiments were carried out in duplicate. The diffusion coefficients $(D)$ were estimated by the time lag method according to Eqn (3), where $I$ is the film thickness and $\theta$ the time lag. The time lag is determined as the intercept of the time axis and the extrapolated linear steady state part of the curve for a representation of the amount of permeant passing through the film in time $t$ versus time.

$$
D=\frac{l^{2}}{6 \theta}
$$

In the helium case, the time lag accounted only for a few seconds causing poor repeatability in its determination. Consequently, the helium diffusion coefficient presented in this work is an approximate value to tentatively compare its order of magnitude with the diffusion coefficient of the other probes.

The solubility coefficients $(S)$ were calculated using the general equation

$$
P=D \times S
$$

where $P$ is the gas permeability.

\section{EA sorption kinetics}

The sorption isotherm of EA was measured at $25^{\circ} \mathrm{C}$ and $0 \% \mathrm{RH}$ with a static method, using an electronic microbalance (Intelligent Gravimetric Analyzer 002, Hiden Isochema Ltd, Warrington,
UK) with a sensitivity of $0.2 \mu \mathrm{g}$. The film samples $(30-60 \mathrm{mg}$ ) were suspended from the microbalance by a stainless steel spiral which was contained in a thermoregulated cell, at $25^{\circ} \mathrm{C}$. The microbalance was maintained at $50^{\circ} \mathrm{C}$ to ensure stability during the weight measurement by the prevention of solvent condensation. Before the measurement, the samples were purged for $24 \mathrm{~h}$ at $10^{-5} \mathrm{mbar}$ to remove all volatile compounds sorbed in the film and present in the chamber. Then the EA partial pressure was set using a pressure transducer (Baratron ${ }^{\circledR}$, MKS Instruments, Wilmington, MA, USA) linked to a tank with a vapour phase saturated in EA. The weight uptake of the sample was recorded automatically against time at 0.2 activity.

The apparent EA solubility $S_{\text {app }}\left(\mathrm{kg} \mathrm{m}^{-3} \mathrm{~Pa}^{-1}\right)$ was calculated according to

$$
S_{\text {app }}=m_{\infty} \times \frac{d}{p}
$$

where $m_{\infty}$ is the equilibrium sorption obtained theoretically after infinite time $\left(\mathrm{kg} \mathrm{kg}^{-1}\right), d$ is the film density $\left(\mathrm{kg} \mathrm{m}^{-3}\right)$ and $p$ the compound vapour partial pressure $(\mathrm{Pa})$. Each sample was measured in duplicate. The microbalance is calibrated regularly during maintenance periods for pressure, weight and temperature. The used methods were previously published by Colomines et al. ${ }^{11}$

\section{Estimation of EA diffusion coefficient}

In the case of formulated PLA, the diffusion coefficient was calculated from

$$
\frac{m_{t}}{m_{\infty}}=\left(\frac{16 \times D}{\pi \times I^{2}}\right)^{1 / 2} \sqrt{t}
$$

where $m_{\infty}$ is the equilibrium sorption obtained theoretically after infinite time $\left(\mathrm{kg} \mathrm{kg}^{-1}\right), m_{t}$ is the weight at time $t(\mathrm{~s})$, I the thickness of the film $(\mathrm{m})$ and $D$ the diffusion coefficient $\left(\mathrm{m}^{2} \mathrm{~s}^{-1}\right)$. In the case of neat non-annealed and recrystallized PLA, the equilibrium was not reached. Consequently the diffusion coefficients were estimated using Eqn (6) from equilibrium state experiments carried out at higher temperature.

\section{Statistical analysis}

The statistical analysis was done with a one-way analysis of variance (ANOVA). When the differences were significant $(P<0.05)$, Fischer's test was used to check the differences between pairs of groups and was carried out using XLSTAT-Pro 7.0 software (Addinsoft, Paris, France). Statistical analysis was carried out separately for neat PLA and formulated PLA.

\section{RESULTS AND DISCUSSION Optimization of crystallization conditions}

The melting temperatures versus the cold crystallization temperatures for neat and formulated PLA are plotted in Fig. 1. The equilibrium melting temperature determined was $173.5^{\circ} \mathrm{C}$ for neat PLA. This temperature decreases with the addition of ATBC and talc to $163.5^{\circ} \mathrm{C}$. The melting point depression is noticeably higher than the one reported by Xiao et al. with $15 \mathrm{wt} \%$ triphenyl phosphate in PLA. ${ }^{53}$

According to the literature, ${ }^{54-57}$ PLA may crystallize during thermal treatment in two forms, the $\alpha$ and $\alpha^{\prime}$ forms. A higher crystallization temperature $\left(T_{\mathrm{C}}>130^{\circ} \mathrm{C}\right)$ induces the formation of the $\alpha$ form whereas a low $T_{\mathrm{C}}\left(80^{\circ} \mathrm{C}<T_{\mathrm{C}}<110^{\circ} \mathrm{C}\right)$ leads to 


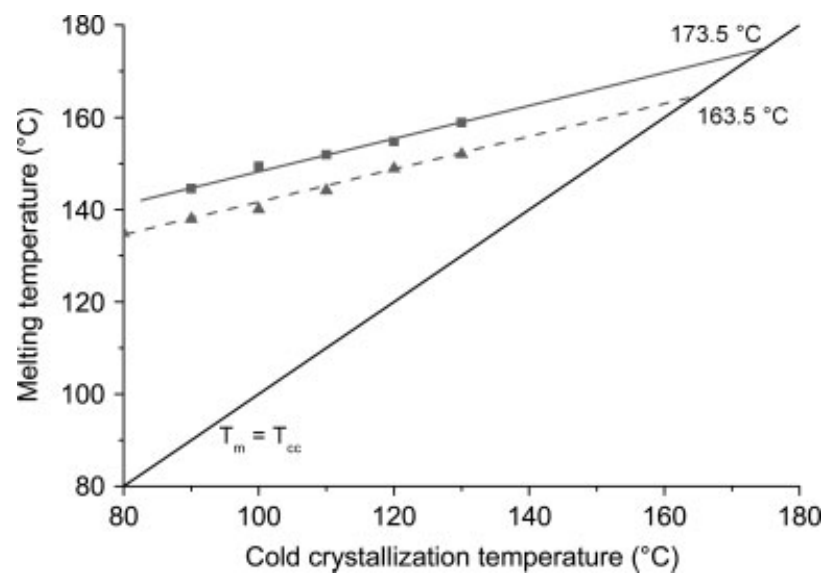

Figure 1. Hoffman-Weeks plots for neat ( $\square$ ) and formulated ( $\mathbf{\Delta})$ PLA.

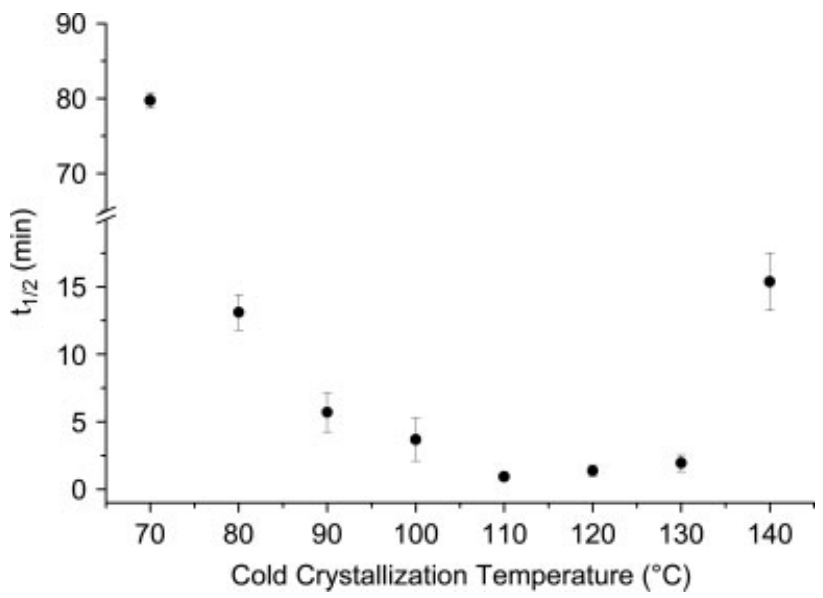

Figure 2. Half-time of crystallization of neat PLA (nPLA) as a function of isothermal cold crystallization temperature.

the formation of the $\alpha^{\prime}$ form (disordered $\alpha$ form). In the range $110-130^{\circ} \mathrm{C}$, the $\alpha$ and $\alpha^{\prime}$ forms coexist. ${ }^{54-56}$

To evaluate the influence of the polymorphism with a constant crystallinity degree on the mechanical and barrier properties, two cold crystallization temperatures were chosen for neat PLA: $90^{\circ} \mathrm{C}$ to obtain the $\alpha$ form and $120^{\circ} \mathrm{C}$ to ensure the formation of the ordered and disordered $\alpha$ form. The degree of undercooling of neat PLA is evaluated at 54 and $35^{\circ} \mathrm{C}$ for 90 and $120^{\circ} \mathrm{C}$, respectively.

As the melting temperature decreases with the formulation, lower cold crystallization temperatures, 85 and $100^{\circ} \mathrm{C}$, were selected to crystallize the formulated samples in the oven. The degree of undercooling of formulated PLA is then evaluated at 52 and $40{ }^{\circ} \mathrm{C}$ for 85 and $100^{\circ} \mathrm{C}$, respectively.

The half-time of crystallization $\left(t_{1 / 2}\right)$ of neat PLA measured in isothermal conditions after cooling from the melt is plotted in Fig. 2 as a function of the cold crystallization temperature. The optimum $t_{1 / 2}, 1.5 \mathrm{~min}$, is measured at $110^{\circ} \mathrm{C}$.

Crystallization isotherms were performed by DSC to determine the crystallization duration to obtain fully crystallized samples. As shown in Fig. 3, the crystallization peak time of neat PLA was observed at 5.9 and $0.5 \mathrm{~min}$, at 90 and $120^{\circ} \mathrm{C}$, respectively. Moreover, as shown in Fig. 2, the half-time of crystallization, at 90 and $120^{\circ} \mathrm{C}$, is below $5 \mathrm{~min}$. Hence, to ensure full crystallization of the sample in the oven, the annealing time was chosen to

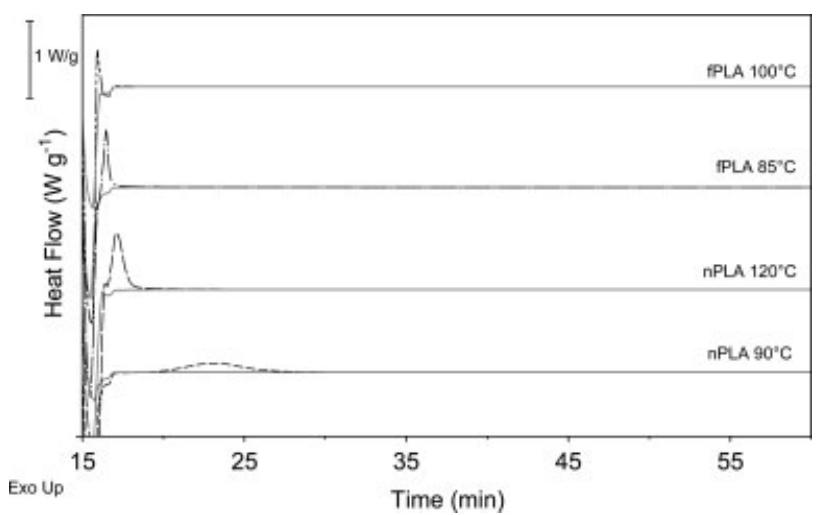

Figure 3. DSC thermograms for neat ( $\mathrm{PLA}$ ) and formulated PLA (fPLA) (black lines) during isothermal cold crystallization at 90 and $120^{\circ} \mathrm{C}$ for neat PLA and 85 and $100^{\circ} \mathrm{C}$ for formulated PLA. The baselines, obtained with sapphire at each crystallization temperature, are grey lines. The curves were vertically shifted for legibility.

be more than 20 times the neat PLA $t_{1 / 2}$, i.e. for $90 \mathrm{~min}$ at both temperatures.

As expected, the formulation increases the crystallization rate. The isotherms of the formulated PLA show a sharp peak at $0.1 \mathrm{~min}$ at $85^{\circ} \mathrm{C}$ (Fig. 3). In the case of crystallization at $100^{\circ} \mathrm{C}$, the crystallization peak was completed after $1.5 \mathrm{~min}$, a time which was completely inside the phase of temperature stabilization of our DSC apparatus. To assess the influence of crystallization duration and crystal perfection, the formulated samples were crystallized for 10 and $30 \mathrm{~min}$ at $85^{\circ} \mathrm{C}$ and 10,30 and $60 \mathrm{~min}$ at $100^{\circ} \mathrm{C}$, which is much larger than the presumed half-time of crystallization of formulated PLA.

\section{Characterization of the crystal structure and mechanical properties}

Results obtained on the crystallinity of the neat and formulated PLA samples recrystallized in the DSC apparatus or annealed in the oven are listed in Table 1. The DSC data show an increase in crystallinity with recrystallization temperature for the neat PLA. Film samples annealed in the oven show smaller crystallinity, most probably due to a less well controlled temperature. In the case of DSC annealing the crystallinity degree reached $52 \%$, whereas in the oven the maximum was recorded at $43 \%$. The crystallization conditions did not lead to a change in the crystallinity degree of the formulated PLA. The crystallinity degree reached around $31 \%$ whatever the crystallization temperature and duration, which was lower than that observed in the case of the neat sample. A decrease in crystallinity with plasticization was also observed by Xiao et al. ${ }^{58}$ for PLA-based blends with triphenyl phosphate. The formulated samples annealed at $85^{\circ} \mathrm{C}$ for $10 \mathrm{~min}$ showed discrepancy between the DSC experiment and samples annealed in the oven, which could be attributed to a temperature gradient in the oven.

PLA is highly sensitive to thermal treatments which may induce a decrease in the molecular weight ${ }^{59,60}$ mainly due to hydrolysis. Therefore, the polymer molecular weights were determined and are given in Table 1. The weight average molecular weights of neat and formulated PLA film are 103000 and $83000 \mathrm{~g} \mathrm{~mol}^{-1}$ respectively, indicating a degradation phenomenon during the blending step. No significant decrease in molecular weight is noticed during the annealing in the oven for the different systems. 

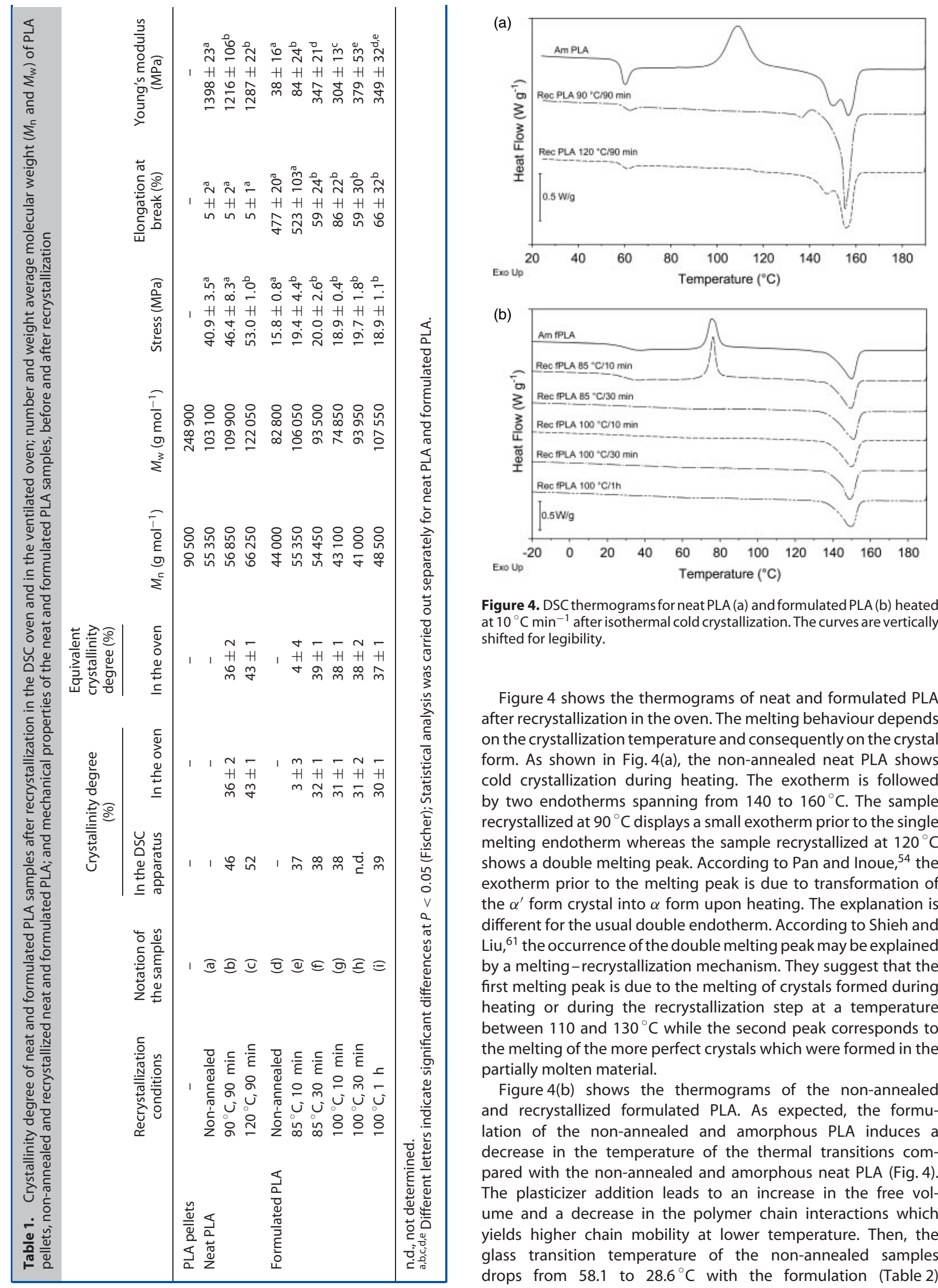

Figure 4. DSC thermograms for neat PLA (a) and formulated PLA (b) heated

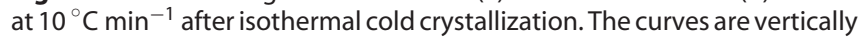
shifted for legibility.

Figure 4 shows the thermograms of neat and formulated PLA after recrystallization in the oven. The melting behaviour depends on the crystallization temperature and consequently on the crystal form. As shown in Fig. 4(a), the non-annealed neat PLA shows cold crystallization during heating. The exotherm is followed by two endotherms spanning from 140 to $160^{\circ} \mathrm{C}$. The sample recrystallized at $90^{\circ} \mathrm{C}$ displays a small exotherm prior to the single melting endotherm whereas the sample recrystallized at $120^{\circ} \mathrm{C}$ shows a double melting peak. According to Pan and Inoue, ${ }^{54}$ the exotherm prior to the melting peak is due to transformation of the $\alpha^{\prime}$ form crystal into $\alpha$ form upon heating. The explanation is different for the usual double endotherm. According to Shieh and $\mathrm{Liu}^{61}$ the occurrence of the double melting peak may be explained by a melting-recrystallization mechanism. They suggest that the first melting peak is due to the melting of crystals formed during heating or during the recrystallization step at a temperature between 110 and $130^{\circ} \mathrm{C}$ while the second peak corresponds to the melting of the more perfect crystals which were formed in the partially molten material.

Figure 4(b) shows the thermograms of the non-annealed and recrystallized formulated PLA. As expected, the formulation of the non-annealed and amorphous PLA induces a decrease in the temperature of the thermal transitions compared with the non-annealed and amorphous neat PLA (Fig. 4). The plasticizer addition leads to an increase in the free volume and a decrease in the polymer chain interactions which yields higher chain mobility at lower temperature. Then, the glass transition temperature of the non-annealed samples drops from 58.1 to $28.6^{\circ} \mathrm{C}$ with the formulation (Table 2) 


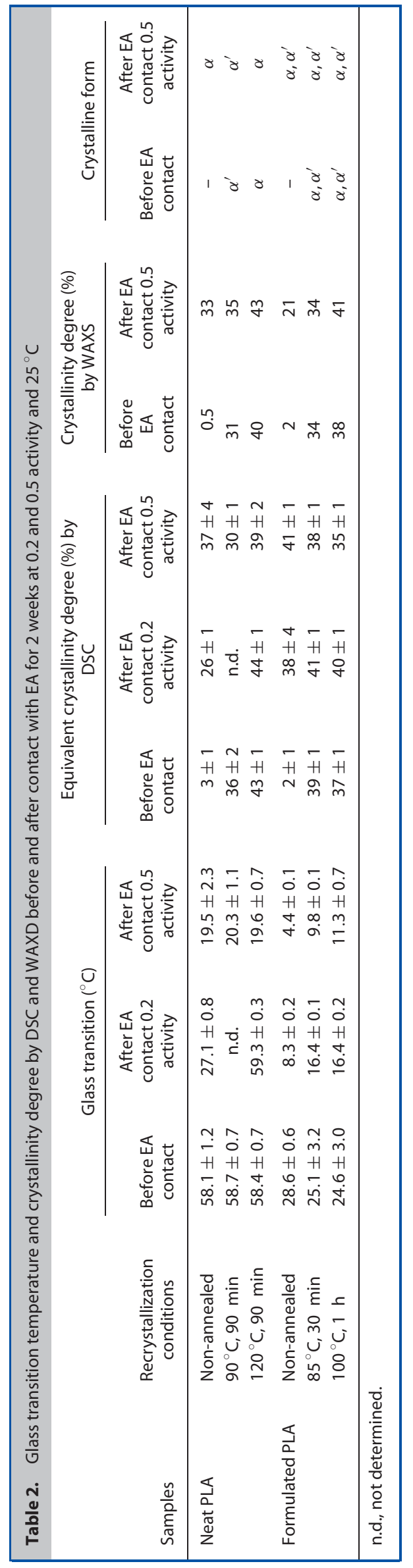

whereas the cold crystallization temperature decreases from 110 to $80^{\circ} \mathrm{C}$.

The formulated recrystallized PLA samples display no cold crystallization peak, except for $85^{\circ} \mathrm{C} / 10 \mathrm{~min}$. The crystallization peak between 70 and $80^{\circ} \mathrm{C}$ is followed by the melting peaks, a small one around $130^{\circ} \mathrm{C}$ and the dominant one at $150{ }^{\circ} \mathrm{C}$. This double endotherm is also visible for the sample recrystallized $10 \mathrm{~min}$ at $100^{\circ} \mathrm{C}$. Apparently, short recrystallization durations do not allow for crystal perfection and therefore show a melting-recrystallization phenomenon, whereas at longer duration perfect $\alpha$ forms are obtained.

The WAXD patterns of neat and formulated recrystallized samples are depicted in Fig. 5. Distinct diffraction peaks were observed for the neat recrystallized samples according to the annealing temperature. As given in the literature, ${ }^{54-56,62}$ the samples recrystallized at $90^{\circ} \mathrm{C}$ exhibit an $\alpha^{\prime}$ crystal structure characterized by intense peaks at $16.5^{\circ}$ and $18.9^{\circ}$, due to the diffraction from (200) and/or (110) planes and from the (203) plane, respectively. Weak reflections are also observed at $12.3^{\circ}$, $14.7^{\circ}$ and $22.2^{\circ}$ due to diffraction from the (103), (010) and (015) planes. A weak peak is seen at $24.7^{\circ}$ which is also characteristic of the $\alpha^{\prime}$ form. ${ }^{57}$

The sample recrystallized at $120^{\circ} \mathrm{C}$ presents a shift of the two most intense peaks to $16.7^{\circ}$ and $19.1^{\circ}$. Moreover these samples show an increase in the intensity of the peaks at $12.3^{\circ}$ and $22.2^{\circ}$ and the appearance of peaks at $20.8^{\circ}, 23.0^{\circ}, 24.0^{\circ}$ and $25.1^{\circ}$ which are fully characteristic of the $\alpha$ form. These data confirm the formation of the $\alpha^{\prime}$ form at low crystallization temperature (below $100^{\circ} \mathrm{C}$ ) and of the $\alpha$ form at higher crystallization temperature (above $\left.120^{\circ} \mathrm{C}\right) .54-56$

The formulated crystallized PLA presented similar WAXD patterns to the neat PLA and the peaks at $9.7^{\circ}$ and $28.6^{\circ}$ (not shown) characteristic of the talc. Whatever the crystallization temperature and time, the formulated samples showed similar $2 \theta$ values and intensities. As shown in Fig. 5, the profile seems similar to that of neat PLA recrystallized at $90^{\circ} \mathrm{C}$ but a slight shift of the peak from $18.9^{\circ}$ to $19.0^{\circ}$ and the appearance of a peak at $23.8^{\circ}$ are noticed. To conclude, the WAXD pattern seems to be a combination of $\alpha$ and $\alpha^{\prime}$ forms whatever the crystallization temperature and time used for the formulated samples.

Therefore, contrary to neat PLA which presents a distinct crystal structure according to the crystallization temperature, the formulated PLA seems not to be affected by the annealing conditions at 85 and $100^{\circ} \mathrm{C}$ by crystallizing under a combination of $\alpha$ and $\alpha^{\prime}$ forms. This absence of modification induced by the formulation and the different annealing conditions is confirmed by Xiao et al. $^{53}$ in the case of triphenyl phosphate and by Piorkowska et al. ${ }^{63}$ with poly(ethylene glycol) and poly(propylene glycol).

Non-annealed neat PLA displays a moderate Young's modulus and maximum stress and a low elongation at break (Fig. 6). ${ }^{47,64-66}$ As shown in Table 1, the recrystallization of neat PLA induces no significant modification of the mechanical properties. The recrystallized neat PLA shows brittle fracture. The elongations at break are below $5 \%$ and the maximum stresses are around $50 \mathrm{MPa}$ whatever the recrystallization temperature. As expected, the formulation with $17 \mathrm{wt} \%$ of ATBC and $1 \mathrm{wt} \%$ of talc leads to a dramatic rise in the elongation at break and a decrease in the maximum stress which reach $477 \%$ and $15.8 \mathrm{MPa}$ respectively (Fig. 6). ${ }^{44,47,48,67}$ The result is due to the addition of plasticizer which facilitates polymer chain slippage during the tensile tests. ${ }^{43}$

Contrary to neat PLA, formulated PLA shows modification in the mechanical properties upon increase of the crystallinity degree. 
(a)

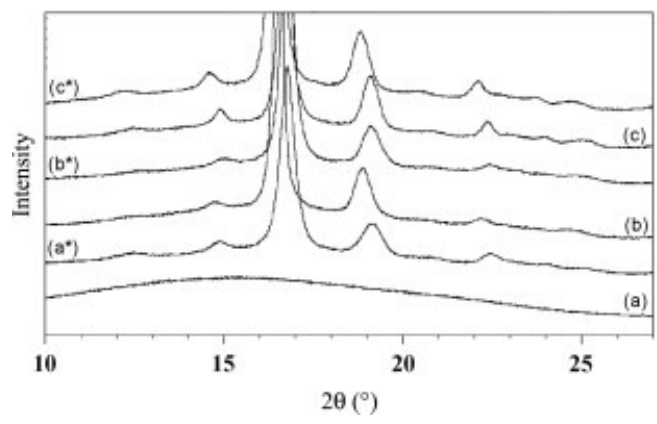

(b)

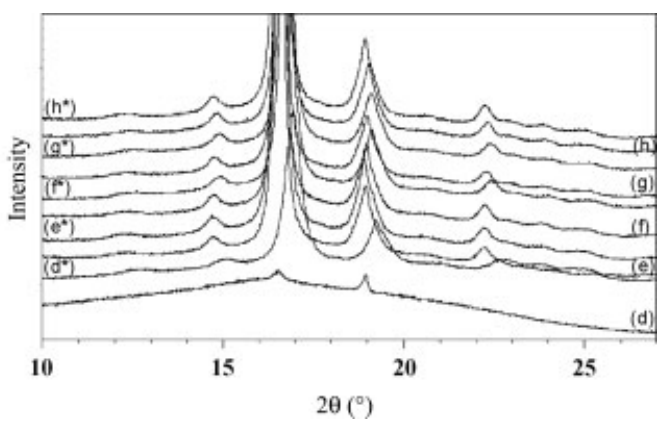

Figure 5. WAXD patterns for (a) neat PLA and (b) formulated PLA before and after contact with EA. The labelling corresponds to the notation in Table 1. The samples after contact are noted with an asterisk.

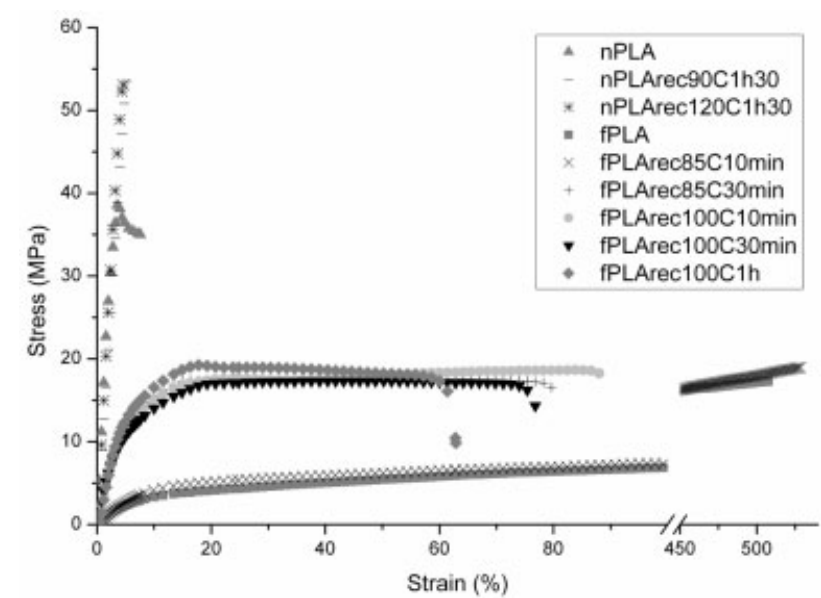

Figure 6. Stress-elongation curves of neat (nPLA) and formulated PLA (fPLA).

At around $30 \%$ crystallinity, the annealed formulated samples show an elongation at break divided by 8 compared with the nonannealed formulated PLA. Moreover the maximum stresses remain steady whereas Young's moduli increase with the recrystallization conditions.

According to Kulinski and Piorkowska, ${ }^{43}$ the diverse lamellae orientations induce different local stresses and strains which may lead to localized fractures. These fractures weaken the plasticized material, which provokes a decrease in the elongation at break. Moreover it has been observed that crystallization of the plasticized PLA exudes the plasticizer into the amorphous phase at the interspherulitic boundaries and at the spherulite peripheries. ${ }^{63}$ This significant local concentration of plasticizer may weaken the links between lamellae or among neighbouring spherulites, thus causing fissures in the case of stress.

\section{Effect of crystallization on the barrier properties}

The helium and oxygen transport coefficients and the EA diffusion and apparent solubility coefficients are listed in Table 3. The well-known Eqn (4) makes it possible to link the permeability coefficient $P$ of helium or oxygen to a kinetic parameter, the diffusion coefficient $D$, and to a thermodynamic parameter, the solubility coefficient $S$. $D$ is related to the polymer structure and takes into account the free volume of the matrix and the tortuosity. $S$ is dependent on the solubility of the gas molecules or aroma compounds in the material. Helium is considered as an inert gas, contrary to oxygen which may interact with the polymer and additives. EA is an organic vapour, and miscible with PLA and ATBC.

As shown in Table 3, the helium permeability coefficients of the non-annealed neat PLA are not significantly modified by the addition of plasticizer and nucleating agent. This is probably due to the low interaction of helium with the matrix and the plasticizer. The crystallization of neat PLA samples induces a significant decrease of the helium permeability coefficient although it keeps the same order of magnitude. This trend is not retrieved in the case of crystallized formulated PLA. The decrease in the gas permeability coefficients is often explained in the literature ${ }^{68}$ by the inclusion of spherulites in the polymer matrix. These impermeable spherulites diminish the amorphous fraction through which the gas molecules can permeate and then affect the gas solubility. Moreover the crystals increase the tortuosity of the gas molecule routes and consequently modify their diffusion coefficients.

Contrary to expectations, the apparent helium diffusion coefficient has an approximate value of $3 \times 10^{-11} \mathrm{~m}^{2} \mathrm{~s}^{-1}$ in neat PLA and seems to increase with crystallization up to $1 \times 10^{-10} \mathrm{~m}^{2} \mathrm{~s}^{-1}$. However, in accordance with expectation, the increase in crystallinity degree of the samples probably affected the apparent solubility coefficient which slightly decreased from $7 \times 10^{-6}$ to $0.7 \times 10^{-6} \mathrm{~Pa}^{-1}$ upon crystallization.

The value of the oxygen permeability of neat non-annealed PLA (Table 3) is in agreement with the literature. ${ }^{7,9,13,69}$ The corresponding diffusion coefficient is close to those obtained by Sawada et al. ${ }^{8,70}$ at $35^{\circ} \mathrm{C}$ but less than those given by Bao et al. ${ }^{69}$ for an amorphous sample at $30^{\circ} \mathrm{C}$. In contrast to helium, the oxygen transport coefficients vary with the formulation. The oxygen permeability and diffusion coefficient doubled and even quadrupled respectively for formulated PLA compared with neat PLA. The oxygen transport properties are affected by the test temperature, which is close to the $T_{\mathrm{g}}$ for the formulated PLA. This may induce an increase of the transport coefficients. Moreover, according to the literature, the diffusion of the gas molecules is closely linked to the free volume of the amorphous phase. Consequently, the rise in the free volume linked to the formulation might induce an increase in the diffusion coefficient and consequently in the permeability coefficient of oxygen for the non-annealed PLA. ${ }^{47,71-73}$

As expected and noticed for helium, the crystallization of neat PLA samples induces a decrease in the oxygen permeability coefficient although it keeps the same order of magnitude. This evolution is not directly linked to crystalline form since, 


\begin{tabular}{|c|c|c|c|c|c|c|c|c|c|}
\hline Samples & $\begin{array}{l}\text { Recrystallization } \\
\text { conditions }\end{array}$ & $\begin{array}{l}\text { Eq. } \chi \\
(\%)\end{array}$ & $\begin{array}{l}\text { Crystalline } \\
\text { form }\end{array}$ & $\begin{array}{c}\mathrm{P}_{\mathrm{He}} \times 10^{18} \\
\left(\mathrm{~m}^{3} \mathrm{~m} \mathrm{~m}^{-2}\right. \\
\left.\mathrm{s}^{-1} \mathrm{~Pa}^{-1}\right)\end{array}$ & $\begin{array}{c}\mathrm{P}_{\mathrm{O} 2} \times 10^{18} \\
\left(\mathrm{~m}^{3} \mathrm{~m} \mathrm{~m}^{-2}\right. \\
\left.\mathrm{s}^{-1} \mathrm{~Pa}^{-1}\right)\end{array}$ & $\begin{array}{c}\mathrm{D}_{\mathrm{O} 2} \times 10^{12} \\
\left(\mathrm{~m}^{2} \mathrm{~s}^{-1}\right)\end{array}$ & $\begin{array}{c}\mathrm{S}_{\mathrm{O}_{2}} \times 10^{6} \\
\left(\mathrm{~m}^{3} \mathrm{~m}^{-3}\right. \\
\left.\mathrm{Pa}^{-1}\right)\end{array}$ & $\begin{array}{c}D_{\text {EA }} \times 10^{17} \\
\left(\mathrm{~m}^{2} \mathrm{~s}^{-1}\right)\end{array}$ & $\begin{array}{c}\mathrm{S}_{\mathrm{EA}} \times 10^{6} \\
\left(\mathrm{~m}^{3}\right. \\
\left.\mathrm{m}^{-3} \mathrm{~Pa}^{-1}\right)\end{array}$ \\
\hline \multirow[t]{3}{*}{ Neat PLA } & Non-annealed & $3 \pm 1$ & - & $100.9 \pm 6.4^{a}$ & $2.30 \pm 0.09^{\mathrm{a}}$ & $1.37 \pm 0.29^{a}$ & $1.7 \pm 0.3^{\mathrm{a}}$ & 2.4 & $1.3 \times 10^{-1}$ \\
\hline & $90^{\circ} \mathrm{C}, 90 \mathrm{~min}$ & $36 \pm 2$ & $\alpha^{\prime}$ & $88.2 \pm 6.9^{b}$ & $1.96 \pm 0.08^{b}$ & $2.21 \pm 0.01^{a}$ & $0.9 \pm 0.1^{b}$ & n.d. & $1.2 \times 10^{-1}$ \\
\hline & $120^{\circ} \mathrm{C}, 90 \mathrm{~min}$ & $43 \pm 1$ & $\alpha$ & $70.7 \pm 1.4^{c}$ & $1.32 \pm 0.16^{b}$ & $2.05 \pm 0.60^{a}$ & $0.7 \pm 0.1^{b}$ & 1.6 & n.d. \\
\hline PLA-2 wt $\%$ talc & Non-annealed & $6 \pm 1$ & - & $110.2 \pm 8.9$ & $2.17 \pm 0.02$ & $2.02 \pm 0.68$ & $1.1 \pm 0.1$ & n.d. & n.d. \\
\hline PLA-17 wt $\%$ ATBC & Non-annealed & $2 \pm 1$ & - & $98.0 \pm 6.7$ & $5.01 \pm 0.29$ & $3.71 \pm 0.67$ & $1.4 \pm 0.2$ & n.d. & n.d. \\
\hline \multirow{4}{*}{$\begin{array}{l}\text { Formulated PLA } \\
\text { (PLA- } 1 \text { wt } \% \text { talc- } 17 \\
\text { wt\% ATBC) }\end{array}$} & Non-annealed & $2 \pm 1$ & - & $106.6 \pm 11.2^{\mathrm{a}}$ & $4.49 \pm 0.95^{\mathrm{a}}$ & $6.03 \pm 1.38^{\mathrm{a}}$ & $0.8 \pm 0.2^{\mathrm{a}}$ & $1 \times 10^{4}$ & 14.5 \\
\hline & $85^{\circ} \mathrm{C}, 30 \mathrm{~min}$ & $39 \pm 1$ & $\alpha, \alpha^{\prime}$ & $97.6 \pm 14.7^{a}$ & $7.10 \pm 0.12^{b}$ & $7.49 \pm 0.12^{\mathrm{a}}$ & $1.0 \pm 0.1^{\mathrm{a}}$ & $5 \times 10^{4}$ & 15.2 \\
\hline & $100^{\circ} \mathrm{C}, 30 \mathrm{~min}$ & $38 \pm 2$ & $\alpha, \alpha^{\prime}$ & $99.0 \pm 6.5^{\mathrm{a}}$ & $6.84 \pm 0.92^{b}$ & $8.10 \pm 0.98^{a}$ & $0.8 \pm 0.1^{\mathrm{a}}$ & n.d. & n.d. \\
\hline & $100^{\circ} \mathrm{C}, 1 \mathrm{~h}$ & $37 \pm 1$ & $\alpha, \alpha^{\prime}$ & $100.9 \pm 7.8^{\mathrm{a}}$ & $7.62^{\mathrm{b}}$ & $9.65^{a}$ & $0.8^{\mathrm{a}}$ & $7 \times 10^{4}$ & 9.4 \\
\hline
\end{tabular}

The helium and oxygen data of PLA with $2 \mathrm{wt} \%$ of talc and PLA with $17 \mathrm{wt} \%$ of ATBC are given as references. n.d., not determined. $a, b, c$ Significant differences at $P<0.05$ (Fischer). Statistical analysis was carried out separately for neat PLA and formulated PLA.

despite different crystalline structures, both neat recrystallized PLAs present similar diffusion coefficients.

In contrast to neat PLA, the oxygen permeability coefficient of formulated PLA increases slightly with crystallization. Crystallization in formulated PLA may induce plasticizer segregation towards the amorphous phase leading to an increase of approximately $30 \%$ of the plasticizer content in the remaining amorphous phase. Courgneau et al..$^{51}$ showed that the oxygen permeability in amorphous PLA evolves with the plasticizer content. Consequently the enhanced oxygen permeability confirms the plasticizer enrichment of the amorphous phase with the crystallization of formulated PLA. Moreover, according to Kulinski and Piorkowska, ${ }^{43}$ the presence of a high content of plasticizer could induce accumulation of plasticizer outside the growing spherulites causing weakness of interspherulitic boundaries. Different local stresses and strains may lead to localized crazing cracks creating routes for transport of the gaseous molecules. This increase in the oxygen permeability may confirm the weakness of the crystallized formulated PLA observed previously by tensile tests. No significant modification of the oxygen diffusion coefficient was noticed with crystallization for neat or formulated PLAs, though. This surprising result might be caused by a dedensification of the amorphous phase or by the appearance of a rigid amorphous fraction created by the PLA crystallization. This dedensification phenomenon has been shown by several authors for $\mathrm{PET}^{74-76}$ and Poly(ethylene naphthalene) PEN ${ }^{77}$ and suggested for PLA. ${ }^{11}$ For instance, Hu et al. ${ }^{77}$ showed that the decrease in amorphous phase density of PEN, resulting from crystallization, caused a significant rise in oxygen diffusion and solubility coefficients of the amorphous phase, thus hindering the improvement of the gas barrier properties of the material. The concept of three phases with a mobile amorphous fraction (MAF), a rigid amorphous fraction (RAF) and a crystalline fraction has also been suggested to explain the evolution of the oxygen diffusion coefficient. In the heterogeneous stack model, the RAF is located between adjacent lamellae within spherulites and hence the MAF is at the interspherulitic boundaries. ${ }^{78}$ Drieskens et al. ${ }^{68}$ suggested that the RAF was less dense than the MAF which could create preferential ways for oxygen molecules through the PLA samples. According to Sawada et al., ${ }^{70}$ increase in the crystallinity degree, i.e. the arrangement of the polymer chains in lamellae, induces the formation of a con- tinuous pathway. In the case of a gas molecule whose volume is smaller than the interlamellar space, diffusion would be facilitated. They showed an increase in permeation for $\mathrm{H}_{2}, \mathrm{O}_{2}, \mathrm{~N}_{2}$ and $\mathrm{CH}_{4}$ in PLA up to $20 \%$ of crystallinity, and a slow decrease starting around $40 \%$. They explained this behaviour by the junction of crystal lamellae. ${ }^{70}$ In our case a decrease of the diffusion coefficient with higher degree of crystallinity was not observed in the case of the neat samples.

We showed furthermore that the oxygen solubility coefficients of neat PLA decrease with increase in the crystallinity degree but without being affected by the crystalline type ( $\alpha$ versus $\alpha^{\prime}$ form). The decrease of the solubility coefficient is an expected result, considering that the creation of crystalline structure lowers the amount of amorphous phase available for gas sorption. Such behaviour has also been experimentally observed in the case of PET. ${ }^{78,79}$

These effects of the crystallization on the diffusion and solubility coefficient contradict the previous results of Drieskens et al., ${ }^{68}$ who reported an oxygen diffusion coefficient divided by 5 and an oxygen solubility coefficient multiplied by 3 with increase of crystallinity degree from 0 to around $40 \%$. However, the results of gas solubility are in accordance with Sawada et al. ${ }^{70}$ who showed a slight decrease of oxygen solubility with crystallization.

Experiments were then carried out with a far more interacting molecule, EA. Already sorption experiments showed a large influence of formulation on the sorption coefficient, which increased by 2 orders of magnitude compared with neat samples probably due to miscibility of EA with ATBC. However, the crystallization of neat and formulated PLA did not modify the apparent EA solubility coefficient. The constancy of the apparent solubility coefficient despite the annealing of neat and formulated PLA is not consistent with the Henry sorption model. ${ }^{11}$ This suggests that at 0.2 activity of EA the structure of the samples is modified during the experiment by contact with the organic compound. As reported by Colomines et al. ${ }^{11}$ and Naga et al., ${ }^{79}$ the contact with organic vapours such as EA leads to plasticization and crystallization (solvent induced crystallization) of the samples.

As in the case of oxygen, the EA diffusion coefficient in neat PLA was not modified by crystallization. The annealing of the formulated samples showed even a slight increase in the EA diffusion coefficient, although values stayed of the same order of 
magnitude. In the EA case, the dedensification hypothesis seemed to be unlikely due to the size of the molecule. Therefore the effect of EA on the PLA structure was investigated more thoroughly by conditioning the different samples in an EA atmosphere at 0.2 activity.

Data on the glass transition and crystallinity degree are given in Table 2. The glass transition was measured during the first heating scan although the enthalpic relaxation peak was superposed on the $T_{\mathrm{g}}$ signal. As already observed by Colomines et al. ${ }^{11}$ EA acts as a plasticizer of PLA, which causes $T_{\mathrm{g}}$ shift near to or even below the measuring temperature of the sorption experiment, i.e. $23^{\circ} \mathrm{C}$. The sorption measurement is in this case done in the glass transition region which most probably explains the observed increase of the diffusion coefficient. Moreover, as shown by Colomines et al., ${ }^{11}$ the thermal recrystallization did not induce any difference in the decrease in $T_{\mathrm{g}}$ of the neat PLA, whereas a gap of $5^{\circ} \mathrm{C}$ is seen between the non-annealed and the annealed formulated PLA.

The assessment of the crystallinity degree shows for the nonannealed samples a strong increase in crystallinity. In order to further study the EA induced crystallization, samples were conditioned in an EA atmosphere at higher activity (0.5) and crystallinity was analysed by DSC and WAXD. The results are summarized in Table 2 and Fig. 5 . The non-annealed neat sample showed a single melting peak in DSC which may be attributed to the formation of the $\alpha$ form by EA contact. This behaviour was confirmed by WAXD which showed the appearance of peaks characteristic of the $\alpha$ form.

In contrast, no modification of the crystallinity degree was observed for the annealed neat PLA, either by DSC or by WAXD. Moreover, these samples exhibit, after EA contact, thermograms and WAXD patterns similar to those before contact, which means that no modification of the crystal structure is induced by EA contact for the annealed neat PLA.

The non-annealed formulated PLA crystallized up to $21 \%$ whereas the annealed formulated PLA did not show any increase in crystallinity degree. The WAXD pattern of non-annealed formulated PLA showed intense peaks after EA vapour contact in agreement with the induced crystallization having both $\alpha$ and $\alpha^{\prime}$ form crystals. No significant modification was observed on the annealed and formulated PLA pattern which means that the EA contact did not modify the structure of the formulated PLA previously crystallized.

\section{CONCLUSIONS}

Crystallization of neat and formulated $P(D, L) L A$ was investigated regarding its impact on barrier properties. Different types of behaviour are noticed according to the probe molecule. In particular, helium is sensitive to the density variation between amorphous and crystalline phases of the polymer matrix, oxygen to the free volume of the amorphous phase and EA presents a high chemical interaction with the polymer.

Hence the helium permeability coefficient decreased with crystallization and was found to be independent of the polymer formulation. Two different behaviours were observed for oxygen transport coefficients. (i) In the case of neat PLA, the permeability coefficient slightly decreases whereas the diffusion coefficient increases with the crystallinity. This behaviour may be explained by the dedensification of the interspherulitic amorphous phase which creates pathways for the oxygen molecules. (ii) In the case of formulated PLA, the permeability coefficient increases upon crystallization due to the plasticizer enrichment of the amorphous phase, resulting in an increase in the oxygen diffusion coefficient. No impact of PLA polymorphism ( $\alpha$ and $\alpha^{\prime}$ form) on gas barrier properties was observed in this work for the two probe molecules. The behaviour of PLA with EA is much more complex because of its interaction with the matrix. The vapour contact with this organic molecule induces the plasticization and the crystallization of amorphous neat PLA in the $\alpha$ form and in a combination of the $\alpha$ and $\alpha^{\prime}$ form in the case of non-annealed formulated PLA. Consequently, in comparison with annealing, the contact with EA vapour appears an easy and innovative way to crystallize PLA into the $\alpha$ form.

The relationship barrier properties-PLA microstructure is complex and dependent on the probe used. To reach a consensus between authors and a clear conclusion, work still needs to be pursued in order to understand the effect of the PLA microstructure on gas barrier properties. Moreover our work highlights the importance of considering the chemical interaction of organic vapours with the PLA structure in the development of PLA commodity applications.

\section{ACKNOWLEDGEMENTS}

The authors thank Cédric Plessis (INRA, UMR 1145) and Jonathan Idrac (LNE, Trappes) for their technical insight and support. The authors are also grateful to Olivier Vitrac (INRA, UMR 1145) for his support in computer programming.

\section{REFERENCES}

1 Bogaert J-C and Coszach P, Macromol Symp 153:287-303 (2000).

2 Ikada Y and Tsuji H, Macromol Rapid Comm 21:117-132 (2000).

3 Gupta AP and Kumar V, Eur Polym J 43:4053-4074 (2007).

4 Shen L, Haufe J and Patel MK, PROBIP 2009, Product Overview and Market Projection of Emerging Bio-Based Plastics. Report commissioned by EPNOE and European Bioplastics http://www.epnoe.eu (2009).

5 Dury-Brun C, Chalier P, Desobry S and Voilley A, Food Rev Int 23:199-255 (2007).

6 Berlinet C, Brat P and Ducruet V, Packag Technol Sci 21:279-286 (2008).

7 Auras R, Harte B and Selke S, J Appl Polym Sci 92:1790-1803 (2004).

8 Komatsuka T, Kusakabe A and Nagai K, Desalination 234:212-220 (2008).

9 Petersen K, Nielsen PV and Olsen MB, Starch/Stärke 53:356-361 (2001).

10 Auras R, Singh SP and Singh JJ, Packag Technol Sci 18:207-216 (2005).

11 Colomines G, Ducruet V, Courgneau C, Guinault A and Domenek S, Polym Int 59:818-826 (2010).

12 Cava D, Giménez E, Gavara R and Lagaron JM, J Plast Film Sheet 22:265-274 (2006).

13 Sanchez-Garcia MD, Gimenez E and Lagaron JM, J Plast Film Sheet 23:133-148 (2007).

14 Auras R, Harte B and Selke S, J Sci Food Agr 86:648-656 (2006).

15 Mauricio-Iglesias M, Peyron S, Chalier P and Gontard N, J Food Eng 10:9-15 (2011).

16 Haugaard V, Weber C, Danielsen B and Bertelsen G, Eur Food Res Technol 214:423-428 (2002).

17 Michaels AS and Bixler HJ, J Polym Sci 50:393-412 (1961).

18 Kanehashi S, Kusakabe A, Sato S and Nagai K, J Membrane Sci 365:40-51 (2010).

19 Sarasua J-R, Prud'homme RE, Wisniewski M, Borgne AL and Spassky N, Macromolecules 31:3895-3905 (1998).

20 Miyata T and Masuko T, Polymer 39:5515-5521 (1998),

21 Di Lorenzo ML, Macromol Symp 234:176-183 (2006).

22 Pluta M and Galeski A, J Appl Polym Sci 86:1386-1395 (2002).

23 Ling $X$ and Spruiell JE, J Polym Sci Pol Phys 44:3378-3391 (2006).

24 Ling XY and Spruiell JE, J Polym Sci Pol Phys 44:3200-3214 (2006).

25 Xiao H, Lu W and Yeh J-T, J Appl Polym Sci 113:112-121 (2009).

26 Lai W-C, Liau W-B and Lin T-T, Polymer 45:3073-3080 (2004).

27 Li Y, Wu H, Wang Y, Liu L, Han L, Wu J, et al, J Polym Sci Pol Phys 48:520-528 (2010)

28 Anderson KS and Hillmyer MA, Polymer 47:2030-2035 (2006). 
29 Schmidt SC and Hillmyer MA, J Polym Sci Pol Phys 39:300-313 (2001).

30 Nam JY, Okamoto M, Okamoto H, Nakano M, Usuki A and Matsuda M, Polymer 47:1340-1347 (2006).

31 Harris AM and Lee EC, J Appl Polym Sci 107:2246-2255 (2008).

32 Kawamoto N, Sakai A, Horikoshi T, Urushihara T and Tobita E, J Appl Polym Sci 103:198-203 (2007).

33 Liao R, Yang B, Yu W and Zhou C, J Appl Polym Sci 104:310-317 (2007).

$34 \mathrm{Li} \mathrm{H}$ and Huneault MA, Polymer 48:6855-6866 (2007).

35 Ke T and Sun X, J Appl Polym Sci 89:1203-1210 (2003).

36 Martin O and Averous L, Polymer 42:6209-6219 (2001).

37 Ljungberg N and Wesslén B, J Appl Polym Sci 86:1227-1234 (2002).

38 Ljungberg $\mathrm{N}$ and Wesslen B, Biomacromolecules 6:1789-1796 (2005).

39 Pillin I, Montrelay N and Grohens Y, Polymer 47:4676-4682 (2006).

40 Martino VP, Ruseckaite RA and Jiménez A, J Therm Anal Calorim 86:707-712 (2006).

41 Martino VP, Jiménez A and Ruseckaite RA, J Appl Polym Sci 112:2010-2018 (2009).

42 Kulinski Z, Piorkowska E, Gadzinowska K and Stasiak M, Biomacromolecules 7:2128-2135 (2006).

43 Kulinski Z and Piorkowska E, Polymer 46:10290-10300 (2005).

44 Baiardo M, Frisoni G, Scandola M, Rimelen M, Lips D, Ruffieux K, et al, J Appl Polym Sci 90:1731 - 1738 (2003).

45 Jacobsen S and Fritz HG, Polym Eng Sci 39:1303-1310 (1999).

46 Hu Y, Hu YS, Topolkaraev V, Hiltner A and Baer E, Polymer 44:5681-5689 (2003).

47 Coltelli M-B, Maggiore ID, Bertoldo M, Signori F, Bronco S and Ciardelli D, J Appl Polym Sci 110:1250-1262 (2008).

48 Labrecque LV, Kumar RA, Davé V, Gross RA and McCarthy SP, J Appl Polym Sci 66:1507-1513 (1997).

49 EFSA, EFSA J 273:1 - 26 (2006).

50 2002/72/EC Commission Directive of 6 August 2002 relating to plastic materials and articles intended to come into contact with foodstuffs, TE Commission, Official Journal 220: 18-58 (2002).

51 Courgneau C, Domenek S, Guinault A, Avérous L and Ducruet V, J Polym Environ 19:362-371 (2011).

52 Fischer EW, Sterzel HJ and Wegner G, Kolloid ZZPolymere 251:980-990 (1973).

53 Xiao HW, Li P, Ren X, Jiang T and Yeh J-T, J Appl Polym Sci 118:3558-3569 (2010)

54 Pan P and Inoue Y, Prog Polym Sci 34:605-640 (2009).

55 Kawai T, Rahman N, Matsuba G, Nishida K, Kanaya T, Nakano M, et al, Macromolecules 40:9463-9469 (2007).
56 Zhang J, Tashiro K, Tsuji H and Domb AJ, Macromolecules 41:1352-1357 (2008).

57 Pan P, Kai W, Zhu B, Dong T and Inoue Y, Macromolecules 40:6898-6905 (2007).

58 Xiao h, Liu F, Jiang T and Yeh J-T, J Appl Polym Sci 117:2980-2992 (2010).

59 Lim LT, Auras R and Rubino M, Prog Polym Sci 33:820-852 (2008).

60 Harris AM and Lee EC, J Appl Polym Sci 115:1380-1389 (2010).

61 Shieh Y-T and Liu G-L, J Polym Sci Pol Phys 45:466-474 (2007).

62 Cho J, Baratian S, Kim J, Yeh F, Hsiao BS and Runt J, Polymer 44:711-717 (2003).

63 Piorkowska E, Kulinski Z, Galeski A and Masirek R, Polymer 47:7178-7188 (2006).

64 Auras R, Harte B and Selke S, Macromol Biosci 4:835-864 (2004).

65 Jia Z, Tan J, Han C, Yang Y and Dong L, J Appl Polym Sci 114:1105-1117 (2009).

66 Murariu M, Ferreira ADS, Alexandre M and Dubois P, Polym Adv Technol 19:636-646 (2008)

67 Yu J, Wang N and Ma X, Biomacromolecules 9:1050-1057 (2008).

68 Drieskens M, Peeters R, Mullens J, Franco D, Lemstra PJ and HristovaBogaerds DG, J Polym Sci Pol Phys 47:2247-2258 (2009).

69 Bao L, Dorgan JR, Knauss D, Hait S, Oliveira NS and Maruccho IM, J Membrane Sci 285:166-172 (2006).

70 Sawada H, Takahashi Y, Miyata S, Kanehashi S, Sato S and Nagai K, Trans Mater Res Soc Japan 35:241 - 246 (2010).

71 McGonigle E-A, Liggat JJ, Pethrick RA, Jenkins SD, Daly JH and Hayward D, Polymer 42:2413-2426 (2001).

72 Ahn J, Chung W-J, Pinnau I and Guiver MD, J Membrane Sci 314:123-133 (2008).

73 Jang J and Lee DK, Polymer 45:1599-1607 (2004).

74 Hu YS, Hiltner A and Baer E, J Appl Polym Sci 98:1629-1642 (2005).

75 Qureshi N, Stepanov EV, Schiraldi D, Hiltner A and Baer E, J Polym Sci Pol Phys 38:1679-1686 (2000).

76 Lin J, Shenogin S and Nazarenko S, Polymer 43:4733-4743 (2002).

$77 \mathrm{Hu}$ YS, Liu RYF, Zhang LQ, Rogunova M, Schiraldi DA, Nazarenko S, et al, Macromolecules 35:7326-7337 (2002)

78 del Rio J, Etxeberria A, Lopez-Rodriguez N, Lizundia E and Sarasua JR, Macromolecules 43:4698-4707 (2010).

79 Naga N, Yoshida Y, Inui M, Noguchi K and Murase S, J Appl Polym Sci 119:2058-2064 (2011). 